University of Wollongong

Research Online

Faculty of Engineering and Information

Faculty of Engineering and Information

Sciences - Papers: Part B

Sciences

2019

Bearing Corrosion Failure Diagnosis of Doubly-fed Induction Generator in Wind Turbines Based on Stator Current Analysis

Xi Chen

Wei Xu

weix@uow.edu.au

Yi Liu

yiliu@uow.edu.au

Md Rabiul Islam

University of Wollongong, mrislam@uow.edu.au

Follow this and additional works at: https://ro.uow.edu.au/eispapers1

Part of the Engineering Commons, and the Science and Technology Studies Commons

Research Online is the open access institutional repository for the University of Wollongong. For further information contact the UOW Library: research-pubs@uow.edu.au 


\title{
Bearing Corrosion Failure Diagnosis of Doubly-fed Induction Generator in Wind Turbines Based on Stator Current Analysis
}

\author{
Abstract \\ IEEE Bearing failure often occurs in doubly-fed induction generator (DFIG)-based wind turbines which are \\ usually subject to electrical corrosion effects. Fault diagnosis method based on electrical signals has \\ been paid much attention as the method is non-invasive and cost-effective. This paper describes the use \\ of the modulation signal bispectrum (MSB) detector for diagnosing bearing faults in DFIGs of wind \\ turbines. The major theoretical principles involved with the MSB method are presented and it is shown \\ how the amplitude and phase relationships of the stator current signals caused by torque oscillations can \\ be effectively revealed. Since the MSB result is obtained by averaging results from each record, \\ overlapped segmentation is proposed to improve computational accuracy with limited data. On site \\ experimental results obtained from $1.5 \mathrm{MW}$ wind turbines corroborate that these faults can be detected, \\ in the current MSB, by the identification of a spectral component at the fundamental frequency and the \\ characteristic frequency. Compared with the other data processing methods based on second-order \\ cumulants, the MSB detector can avoid misdiagnosis by containing phase information of stator current. \\ Owing to relatively high accuracy, the proposed current based MSB method can identify incipient bearing \\ corrosion failure in DFIG-based wind turbines without additional sensors, which also has great potential in \\ other industrial applications.

\section{Disciplines} \\ Engineering | Science and Technology Studies

\section{Publication Details} \\ X. Chen, W. Xu, Y. Liu \& M. Islam, "Bearing Corrosion Failure Diagnosis of Doubly-fed Induction Generator \\ in Wind Turbines Based on Stator Current Analysis," IEEE Transactions on Industrial Electronics, vol. In \\ Press, 2019.
}




\title{
Bearing Corrosion Failure Diagnosis of Doubly-fed Induction Generator in Wind Turbines Based on Stator Current Analysis
}

\author{
Xi Chen, Member, IEEE, Wei Xu, Senior Member, IEEE, Yi Liu, Member, IEEE, \\ and Md. Rabiul Islam, Senior Member, IEEE
}

\begin{abstract}
Bearing failure often occurs in doubly-fed induction generator (DFIG)-based wind turbines which are usually subject to electrical corrosion effects. Fault diagnosis method based on electrical signals has been paid much attention as the method is non-invasive and cost-effective. This paper describes the use of the modulation signal bispectrum (MSB) detector for diagnosing bearing faults in DFIGs of wind turbines. The major theoretical principles involved with the MSB method are presented and it is shown how the amplitude and phase relationships of the stator current signals caused by torque oscillations can be effectively revealed. Since the MSB result is obtained by averaging results from each record, overlapped segmentation is proposed to improve computational accuracy with limited data. On site experimental results obtained from $1.5 \mathrm{MW}$ wind turbines corroborate that these faults can be detected, in the current MSB, by the identification of a spectral component at the fundamental frequency and the characteristic frequency. Compared with the other data processing methods based on second-order cumulants, the MSB detector can avoid misdiagnosis by containing phase information of stator current. Owing to relatively high accuracy, the proposed current based MSB method can identify incipient bearing corrosion failure in DFIG-based wind turbines without additional sensors, which also has great potential in other industrial applications.
\end{abstract}

Index Terms-Bearing failure, doubly-fed induction generator (DFIG), electrical corrosion, fault diagnosis, modulation signal bispectrum, stator current, wind turbine.

Manuscript received October 2, 2018; revised January 6, 2019 and April 8, 2019; accepted May 6, 2019. This work was supported in part by the National Natural Science Foundation of China under Grants 51707079 and 51877093; and in part by the National Key Research and Development Program of China under Grant 2018YFE0100200.

X. Chen, W. Xu and Y. Liu are with the State Key Laboratory of Advanced Electromagnetic Engineering and Technology, School of Electrical and Electronic Engineering, Huazhong University of Science and Technology, Wuhan, 430074, China (e-mail: eechenxi@gmail.com: weixu@hust.edu.cn; liuyi82@hust.edu.cn).

M. R. Islam is with the School of Electrical, Computer, and Telecommunications Engineering, University of Wollongong, Wollongong, Australia (e-mail: mrislam@uow.edu.au).

Corresponding author: Yi Liu (e-mail: liuyi82@hust.edu.cn).

\section{INTRODUCTION}

$\mathrm{W}$ IND turbines are usually installed in remote areas to capture more wind energy and to save land rental cost [1]. The windy, rainy, and sunny environment in these remote areas introduces new challenges for the operation of wind turbines [2]. Such an extreme working environment may lead to higher failure rates, which causes revenue loss due to repair costs and unexpected downtime. Potential failures of wind turbines can be diagnosed or even prognosed from the changes in their parameters [3]. Condition monitoring is necessary to prevent the deterioration of incipient faults by early warning [2].

A bearing is commonly used to support the rotating shaft of the generators, which is considered as one of the most critical components in a wind turbine [4]. With continuous rotation of the generator shaft, a bearing may wear and then cause fatigue, cracking, and even breakage of certain parts. Owing to the variable speed constant frequency, doubly-fed induction generators (DFIGs) are widely used in wind power generation systems. The use of pulse width modulation (PWM) in rotor side converters may lead to electrical corrosion of the bearing of a DFIG, which significantly accelerates bearing wear [5]. Severe bearing failures may cause catastrophic faults in other components in a wind turbine subsystem, such as shaft cracking, gearbox failure and even damage to the generator. Therefore, early detection of bearing failures is necessary to prevent severe damage and reduce revenue loss.

A number of traditional diagnosis methods have been used in wind turbine systems to detect bearing faults, e.g. methods based on the analysis of the vibration signal, the acoustic signal, the temperature, and the lubrication oil parameter [6]. However, all of these diagnostic methods need signal acquisition devices with a high sampling rate. In addition, signals may be attenuated or interfere in the transmission process between defective components and sensors. Hence, electrical signal based analysis methods have received more attention in recent years due to their being non-invasive and cost-effective [7]. Current signals in an electrical machine are continuously detected by current sensors in the power converter to control active and reactive power. Therefore, current-based condition monitoring and fault diagnosis may eliminate the requirements of additional hardware, which confers economic benefit and offers the potential for adoption in wind power generation 
systems.

Since the bearing is mechanically coupled with the electric machine, certain frequency components of the current can be monitored as an index to determine the failure due to torque variation [8] or rotor eccentricity [9]. Different data processing methods have been widely investigated to extract useful information from current signals with a low signal to noise ratio (SNR) [6]. Some conditioning methods are usually applied to raw signals in the time-domain to facilitate the extraction of fault features in the signals. For example, envelope analysis can outline the extremes of a signal, which is also called the amplitude modulating component of the signal [10]. The Hilbert transform is a classical method to compute the instantaneous amplitude and phase of a signal, which has been primarily used for signal demodulation combined with envelope analysis [11]. The envelop spectrum obtained from Hilbert transformation has been proved to be effective in bearing fault diagnosis based on current signals if the mechanical characteristic frequency rate is low [12]. Empirical mode decomposition and the Hilbert-Huang transform (HHT) have also been used for current-based fault diagnosis to highlight the time-frequency representation of intrinsic mode functions [13]. To classify the fault location in a bearing, the current signal (time-domain) should be transformed to the frequency-domain to extract various features. In industrial applications, Fourier analysis is probably the most popular analysis technique. Thus, the fast Fourier transform (FFT) is usually applied to obtain the frequency spectrum [14]. The Extended Park's Vector Approach (EPVA) uses the frequency spectrum of the Park's vector module to improve the SNR of the current signals by converting the fundamental component to the DC component, which successfully detects different types of bearing faults [15]. Considering the energy of such signals, the power spectrum can be introduced to evaluate the power within the unit frequency band [16]. Several improved methods have been proposed to increase the accuracy and frequency resolution of power spectra, e.g., the spectral kurtosis algorithm [10], the Welch power spectrum analysis [17], the root-MUSIC method [18] and noise cancellation [19]. However, the Fourier transform cannot indicate how the frequency content of a non-stationary signal changes. To overcome this drawback, the resampling technique and short-term Fourier transform (STFT) have been proposed for analysing the time-varying frequency response [20], [21]. The wavelet transform is a multiscale analysis method that can improve the constant time-frequency resolution of the STFT, which is capable of grasping both the time and frequency information in a signal [22]. The optimised stationary wavelet packet transform has been proposed in [23] to decrease the computational intensity and simplify the interpretation of results. Moreover, data processing according to the model-based and probability-based method has been applied to signals with low resolution [24], [25]. Recently, AI techniques have also been introduced to bearing fault diagnosis based on electrical signals, such as Artificial Neural Networks (ANNs), support vector machines (SVMs), expert systems, and fuzzy logic systems [23], [26], [27]. Although these AI algorithms can identify fault modes and locations from large amounts of data, the requirement of data storage and computation is also increased. However, previous reports focus on the amplitude and frequency of current signals and ignored the important information conveyed in the phases of signal harmonics. Since bearing faults can generate non-linear harmonics in a vibration signal, non-linear phase coupling will be an essential feature [28]. Higher-order spectra have been developed to deal with the non-Gaussian or non-linear processes by revealing information about amplitude and phase in a stochastic process, whereas phase relationships between frequency components are suppressed in the power spectrum as defined in terms of second-order statistics of a signal [29]. A particular case of higher-order spectra is the third-order spectrum, i.e. the bispectrum, which is the Fourier transform of the third-order statistics and incurs the lowest computation cost among such higher-order spectra. To avoid misleading results, a modulation detector is applied to revise the estimation of the bispectrum [30]. Therefore, the bispectrum estimation and its modulated signal have been utilised in diagnosis of incipient bearing faults based on the vibration signal [31]. Recently, the modulation signal bispectrum (MSB) detector has successfully identified failures caused by electrical imbalance based on electrical signals in laboratory experiments [32].

To the best knowledge of the authors, no report is available on the detection of bearing defects using the bispectrum or MSB method based on electrical signals. The main constraints of this method for industrial applications are: long sampling time, high demand for data size and strict data acquisition conditions. In this research, the MSB method is modified to detect bearing corrosion failure of wind turbines with limited sampling time and data. Differing from previous methods that recorded a large segment of data and divided the data into several periods, we propose an overlapped segment method to use the recorded data in a converter. Moreover, the samplings are triggered only at the cut-in and rated speeds of the wind turbine, which are relatively constant according to the power curve thereof. In addition, all electrical signals are converted to per unit values before calculation in this comparative study and live condition monitoring to evaluate the fault severity between different types of wind turbines. Consequently, the proposed improvements combined with the modulation bispectrum detector can provide bearing fault diagnoses based on electrical signals. Even though the MSB method is not applicable in non-stationary condition, it still shows advantages in detecting the non-linear phase coupling of current signals. The distinct advantage of the MSB detector (i.e. reducing misinformation, especially for the incipient faults) can be further illuminated by critical comparison of four data processing methods for the specific case of bearing fault diagnosis based on current signals. Therefore, the proposed MSB detector-based method could be more accurate than the other current based bearing fault diagnosis methods.

This paper presents a novel bearing fault monitoring technique based on electrical signal analysis for wind turbines. To detect the non-linear phase coupling, the MSB method is used to analyse one phase of the DFIG stator current. The remainder of this paper is organised as follows: Section II 
elaborates upon the mechanism of bearing fault caused by electrical corrosion and the physical link between bearing corrosion and current signal. In Section III, the MSB algorithm and its merits in bearing fault diagnosis are presented. In Section IV, the proposed signal acquisition and processing methods are introduced to fit the site conditions. Afterwards, diagnostic results based on the MSB method for $1.5 \mathrm{MW}$ wind turbines are illustrated in Section V, and then, the comparative study of diagnostic methods for stationary signals is presented in Section VI. Finally, conclusions are drawn in Section VII.

\section{PRinciple of Bearing Fault Detection Caused by ELECTRICAL CORROSION}

\section{A. Electrical Corrosion of the Bearing}

As a common fault, the bearing fault distribution varies between $40 \%$ - 90\% from large to small machines [33]. Some possible causes, such as electric corrosion, lubricant impurities, misalignment in assembly and the overall vibration, may lead to cracks, pits, and spalls on the rolling surface [34]. Among all the above root causes of bearing faults, the shaft voltages and the associated bearing currents are the most common causes of accelerated bearing degradation [5].

Bearing currents may be caused by electrostatic charging and magnetic flux asymmetries in electrical machines [35]. With rapid development of power electronics, the power converter has become another essential source of bearing currents [36]: because of the common mode signal associated with PWM switching, bearing currents can be induced by the high rate of voltage change $(\mathrm{d} V / \mathrm{dt})$ and electrical discharge machining (EDM). The EDM current caused by overvoltage will lead to electrical corrosion of bearings [37]. The common mode voltage $V_{\text {com }}$ that the power converter outputs is defined by

$$
V_{\text {com }}=\frac{V_{a}+V_{b}+V_{c}}{3}
$$

where $V_{a}, V_{b}$ and $V_{c}$ are phase output voltages of the converter.

Unlike the sum of the three phase sinusoidal symmetrical voltages being equal to zero, the $V_{\text {com }}$ produced by the PWM converter does not instantaneously sum to zero. The value of $V_{\text {com }}$ is determined by both the DC bus voltage and the modulation mode [38]. For the DFIG, the rotor side converter can supply the common mode voltage $V_{\text {comr }}$ between the rotor winding and the ground, meanwhile, the grid side converter also can supply the common mode voltage $V_{\text {coms }}$ between the stator winding and the ground. As the stray capacitances construct the coupling circuit, common mode currents will be induced in the DFIG. Classified according to conductivity, four kinds of conductors (the stator windings, the rotor windings, the stator core, and the rotor core) are present in the DFIG. Between any two of the four conductors, there will be a parasitic coupling capacitance. Consequently, the complete parasitic circuit of the DFIG is as shown in Fig. 1(a), where $C_{r w s r}, C_{r w r}$, and $C_{r w f}$ are the parasitic capacitances for the rotor winding to stator winding, the rotor winding to rotor core, and the rotor winding to stator frame, $C_{r f}, C_{s w r}$, and $C_{s w f}$ are those for the rotor core to stator frame, the rotor core to stator winding, and the stator winding to stator frame, $C_{\text {bearing }}$ and $C_{c a p}$ are those for the bearing and its insulation cap, $R_{b r u s h}$ and $L_{b r u s h}$ are the equivalent resistance and inductance of the grounding brush, respectively. In this circuit, $C_{r w f}$ and $C_{s w f}$ are in parallel with the common mode voltage source respectively, which should be short circuited. Moreover, the values of $C_{r w s r}, C_{r w f}$ and $C_{s w r}$ are much smaller than those of $C_{s w f}$ and $C_{r w r}$ in the presence of the air-gap. Thus, the voltage between the shaft and ground mainly depends on $V_{\text {comr }}$. The simplified circuit neglecting the $C_{r w s r}$ and $V_{\text {coms }}$ is shown in Fig. 1(b), from which the voltage value between inner and outer raceways, regardless of the grounding, brush can be expressed as
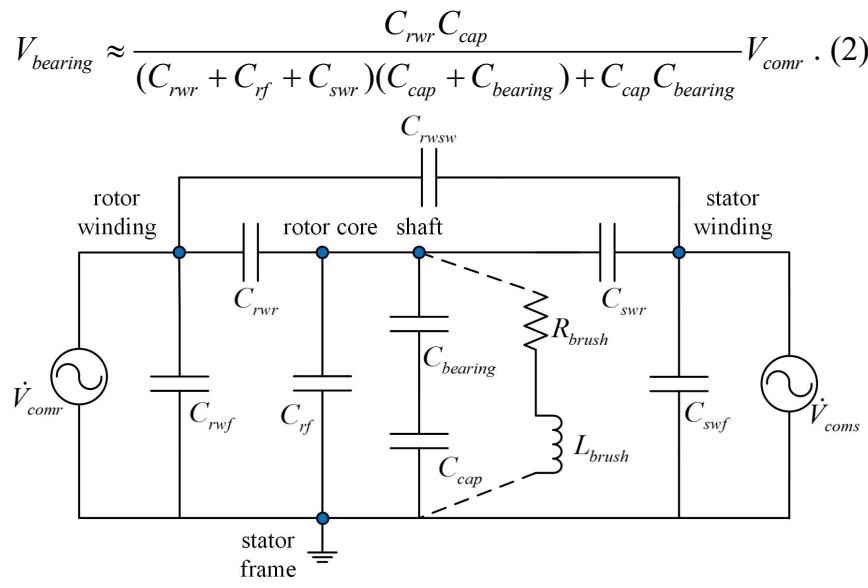

(a)

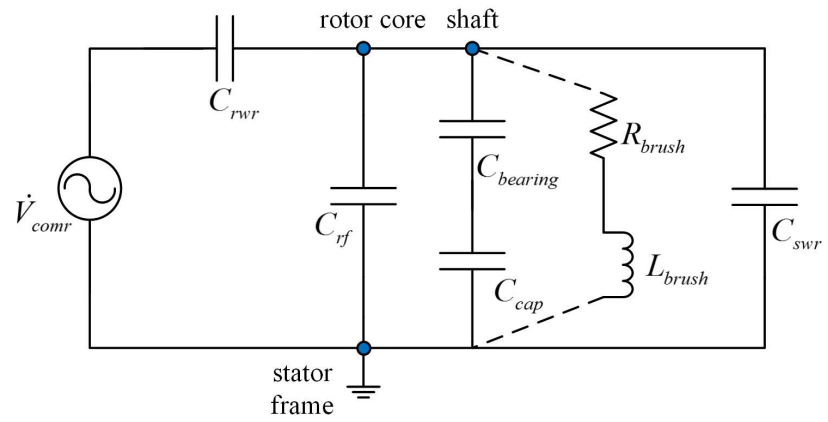

(b)

Fig. 1. Parasitic circuit of the DFIG: (a) the complete circuit and (b) the simplified circuit.

The threshold voltage of the bearing oil has been reported to be approximately 5 to $30 \mathrm{~V}$ [39]. If $V_{\text {bearing }}$ (Fig. 2) exceeds this threshold, the film will break down. Then, the emergent energy produced by EDM current may cause denaturalisation of grease and result in small pits on the surface of the raceway and balls.

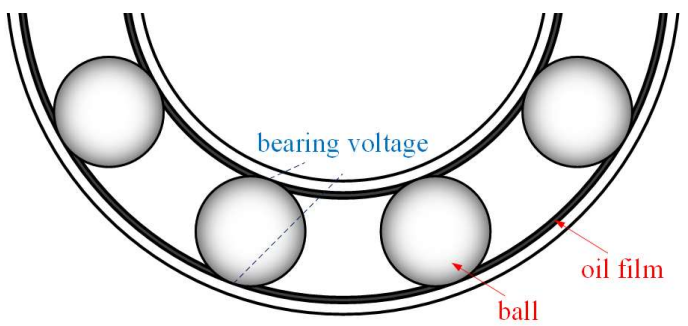

Fig. 2. Mechanism of the bearing corrosion.

Since the capacitive voltage of the DFIG bearing is greater 
than that of the traditional stator-side inverter-fed machines, the bearing of the DFIG will be more likely to suffer the effects of common mode current. One common way in which to ensure a minimal shaft voltage is to use the shaft grounding by means of one or more grounding brushes, which may avoid the damaging current circulating through the bearing to its pedestal [5], [40].

\section{B. Stator Current Signature due to Bearing Faults}

The grounding brush cannot completely avoid the shaft current of the generator for the non-ideal impedance, and consequently long-term electrical corrosion may lead to fatigue or wear of the ball bearings. Then, the small abrasions on the bearings will develop into cracks or breakages on the surface of the raceway. When the roller ball passes through a crack, a slight collision will cause an impact wave at the natural frequency of the bearing system. The number of collisions per period can be called the fault characteristic frequency. For bearing faults in different locations (Fig. 3), the characteristic frequencies can be expressed as [41]

$$
\begin{gathered}
f_{i}=\frac{1}{2} N_{B} f_{r}\left(1+\frac{D_{b} \cos \theta}{D_{c}}\right) \\
f_{o}=\frac{1}{2} N_{B} f_{r}\left(1-\frac{D_{b} \cos \theta}{D_{c}}\right) \\
f_{b}=\frac{1}{2} f_{r}\left(\frac{D_{c}}{D_{b}}\right)\left[1-\left(\frac{D_{b} \cos \theta}{D_{c}}\right)^{2}\right] \\
f_{c}=\frac{1}{2} f_{r}\left(1-\frac{D_{b} \cos \theta}{D_{c}}\right)
\end{gathered}
$$

where $f_{i}, f_{o}, f_{b}$, and $f_{c}$ are the charctersitc frequencies of the inner raceway, outer raceway, ball, and cage, respectively; $f_{r}$ is the rotating frequency of the bearing, $N_{B}$ the number of balls in the bearing, $D_{b}$ the ball diameter, $D_{c}$ the pitch or cage diamter, and $\theta$ the contact angle, respectively.
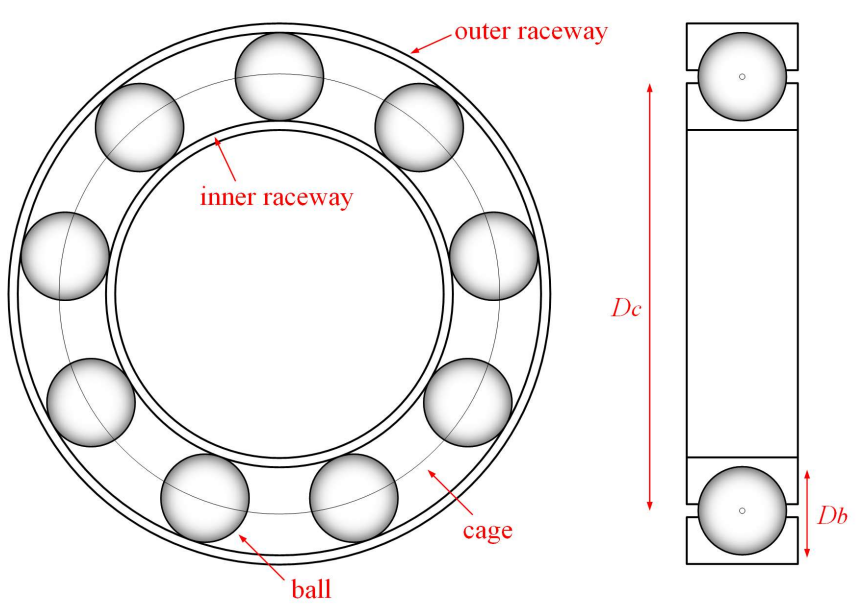

Fig. 3. Configuration of the ball bearing.

Collision in such bearings will couple to the coaxial connected generator and further causes torque variation. As a result, the torque of the DFIG can be modulated by different bearing failures to [20]

$$
T(t)=T_{0}(t)+\sum T_{v} \cos \left(2 \pi f_{\text {fault }} t+\varphi_{v}\right)
$$

where $T_{0}$ is the torque produced by wind power, $T_{v}$ and $\varphi_{v}$ are the amplitude and phase of torque variation due to bearing faults, and $f_{\text {fault }}$ is the fault characteristic frequency of the bearing, respectively.

Since the electromagnetic torque is the product of flux and current, the torque oscillation resulting from rotor eccentricity will lead to amplitude modulation (AM) and quadratic phase coupling (QPC) of current. The modulated phase current in stator windings can be described as [42]

$$
\begin{aligned}
& I_{s a}=I_{0} \sin \left(\omega_{s} t+\varphi_{0}\right)+\sum_{i=1}^{n} I_{i+} \cos \left[\left(\omega_{s}+i \omega_{\text {fault }}\right) t+\left(\varphi_{0}+\varphi_{i}\right)\right] \\
& +\sum_{i=1}^{n} I_{i-} \cos \left[\left(\omega_{s}-i \omega_{\text {fault }}\right) t+\left(\varphi_{0}-\varphi_{i}\right)\right]
\end{aligned}
$$

where $\omega_{s}=2 \pi f_{s}, \omega_{\text {fault }}=2 \pi f_{\text {fault }}, f_{s}$ is the fundamental frequency of the stator current, $I_{0}$ and $\varphi_{0}$ are the amplitude and phase of the fundamental current, and $I_{i \pm}$ and $\left(\varphi_{0} \pm \varphi_{i}\right)$ are the amplitude and phase of the modulation harmonics, respectively.

From (8), the frequency and phase of harmonic components in the stator current caused by bearing corrosion can be expressed as

$$
\begin{gathered}
f_{\text {bearing }}=f_{s} \pm i f_{\text {fault }} \\
\varphi_{\text {bearing }}=\varphi_{0} \pm \varphi_{i} .
\end{gathered}
$$

The phases of the two sideband components in (8) consist of the sum and difference of $\varphi_{0}$ and $\varphi_{i}$, so this type of interaction is generally referred to as QPC. The distinctive feature of harmonic components, thereby, provides a possible solution to judgment of the bearing failure based on stator current signals.

\section{Modulation Signal BISPECTRUM ANALYSIS}

As illustrated in the Introduction section, several methods have been proposed with which to analyse the power spectra and the envelope of the electrical signal, such as use of the FFT, wavelet analysis, HHT, etc. However, all of these algorithms cannot take advantage of the special feature of symmetrical sideband components in the modulated current described by (8). The bispectrum analysis, which is a non-linear signal processing method based on high-order statistic, is commonly used to reveal the QPC from raw data; however, traditional bispectrum detectors may produce incorrect and misleading results, which interferes with the judgment made in fault diagnosis. To avoid omissions and misdiagnoses, the MSB and its normalised form are proposed in (11) and (12) [30]:

$$
\begin{gathered}
B\left(f_{m}, f_{c}\right)=E\left\{X\left(f_{c}+f_{m}\right) X\left(f_{c}-f_{m}\right) X^{*}\left(f_{c}\right) X^{*}\left(f_{c}\right)\right\}(11) \\
b\left(f_{m}, f_{c}\right)=\frac{\left|B\left(f_{m}, f_{c}\right)\right|^{2}}{E\left\{\left|X\left(f_{c}\right) X\left(f_{c}\right)\right|^{2}\right\} E\left\{\left|X\left(f_{c}+f_{m}\right) X\left(f_{c}-f_{m}\right)\right|^{2}\right\}}
\end{gathered}
$$

where $X(f)$ is the discrete Fourier transform (DFT) of a discrete time current signal $x(k), E(X)$ is the statistical expectation operator of the random variable $X$, superscript $*$ denotes the complex conjugate, $f_{c}$ and $f_{m}$ are the carrier and modulation wave frequencies, respectively. $X(f)$ can be defined as 


$$
X(f)=\sum_{k=-\infty}^{\infty} x(k) e^{-j 2 \pi f k} .
$$

Differing from normal bispectral analysis, the MSB detector searches for the carrier frequency and its modulated frequency of $f_{c} \pm f_{m}$ : to recognize the fault characteristic frequency $f_{\text {fault }}\left(f_{m}\right)$, Eq. (11) needs to be expanded to

$$
\begin{aligned}
& B\left(f_{m}, f_{c}\right)=E\left\{\left|X\left(f_{c}+f_{m}\right)\right| e^{j \angle X\left(f_{c}+f_{m}\right)} \cdot\right. \\
& \left.\left|X\left(f_{c}-f_{m}\right)\right| e^{j \angle X\left(f_{c}-f_{m}\right)} \cdot\left|X\left(f_{c}\right)\right| e^{-j \angle X\left(f_{c}\right)} \cdot\left|X\left(f_{c}\right)\right| e^{-j \angle X\left(f_{c}\right)}\right\}
\end{aligned}
$$

Then, Eq. (14) can be rewritten as

$$
\begin{aligned}
& B\left(f_{m}, f_{c}\right)=E\left\{\left|X\left(f_{c}+f_{m}\right)\right|\left|X\left(f_{c}-f_{m}\right)\right|\left|X\left(f_{c}\right)\right|\left|X\left(f_{c}\right)\right|\right. \\
& \left.e^{j\left(\angle X\left(f_{c}+f_{m}\right)+\angle X\left(f_{c}-f_{m}\right)-\angle X\left(f_{c}\right)-\angle X\left(f_{c}\right)\right)}\right\}
\end{aligned} .
$$

If the phase coupling occurs in sideband frequency components, the following relationship can be obtained:

$$
\angle X\left(f_{c} \pm f_{m}\right)=\angle X\left(f_{c}\right) \pm \angle X\left(f_{m}\right) .
$$

Then, Eq. (14) can be simplified to

$$
B\left(f_{m}, f_{c}\right)=E\left\{\left|X\left(f_{c}+f_{m}\right)\right|\left|X\left(f_{c}-f_{m}\right)\right|\left|X\left(f_{c}\right)\right|\left|X\left(f_{c}\right)\right|\right\}
$$

Therefore, if a current signal is composed of components with $f_{c} \mathrm{~Hz}$ and $\left(f_{c} \pm f_{m}\right) \mathrm{Hz}$ and phases are coupled, the MSB detector will reaches its peak value in $B\left(f_{m}, f_{c}\right)$. For current components without phase coupling, the expectation in (15) approaches zero after taking the average of all such segmented samples. As a result, the MSB method is effective in deducing modulated components in current signals from which noise has been eliminated. By combing the physical models of the electric machine described in (7) and (8), the fault characteristic frequency of the bearing can be calculated from current signals.

To use the MSB detector in wind turbines without additional hardware, the conventional direct method, which may be seen as a direct approximation of the definition of higher order spectra in [29], can be modified. As dictated by the expectation operators, the normalised form of (12) is calculated for each set of data and then averaged, however, the amount of recorded data from converters in wind turbines is limited. To increase the accuracy of the MSB result, the data of one phase current should be divided into several segments with an overlapped number of $L$. Hence, the number of segments within one period of data can be expressed as

$$
K=\frac{N-M}{M-L}+1
$$

where $N$ is the total number of data points, and $M$ is the number of samples in each segment. The coefficient of the DFT for $i^{\text {th }}$ segment of data $\left\{x^{(i)}(k), k=0,1,2, \ldots, M-1\right\}$ is then

$$
Y^{(i)}(\lambda)=\frac{1}{M} \sum_{k=0}^{M-1} x^{(i)}(k) \mathrm{e}^{-j 2 \pi k \lambda / M}
$$

where $\lambda=0,1,2, \ldots, M / 2$ and $i=1,2, \ldots, K$.

Supposing that $M=\left(2 L_{1}+1\right) N_{0}$, the MSB estimate formed by the DFT coefficients in each segment is

$$
\begin{aligned}
& \hat{b}_{m s}\left(\lambda_{m}, \lambda_{c}\right)=\frac{1}{\Delta_{0}^{2}} \sum_{k_{m}=-L_{1}}^{L_{1}} \sum_{c}^{L_{1}=-L_{1}} Y^{(i)}\left(\lambda_{c}+k_{c}+\lambda_{m}+k_{m}\right) \\
& Y^{(i)}\left(\lambda_{c}+k_{c}-\lambda_{m}-k_{m}\right) Y^{(i) *}\left(\lambda_{c}+k_{c}\right) Y^{(i) *}\left(\lambda_{c}+k_{c}\right)
\end{aligned}
$$

where $\Delta_{0}=F_{S} / N_{0}$ is the required spacing between frequency samples in the bispectrum domain, and $F_{s}$ the sampling frequency.

The modulated bispectrum estimation of the given data is the average over all $K$ pieces as follows:

$$
\hat{B}_{m s}\left(\omega_{m}, \omega_{c}\right)=\frac{1}{K} \sum_{i=1}^{K} \hat{b}_{m s}\left(\omega_{m}, \omega_{c}\right)
$$

where $\omega_{m}=\left(2 \pi f_{m} / N_{0}\right) \lambda_{m}$ and $\omega_{c}=\left(2 \pi f_{c} / N_{0}\right) \lambda_{c}$.

\section{ANALYSIS OF FIELD CONDITIONS}

The proposed calculation method based on the MSB algorithm is tested on a wind farm with 33 wind turbines. All of these wind turbines, each of which consists of a three-stage gearbox and a 1.5 MW DFIG, have been running for five years. Rated parameters of the generator are as follows: stator voltage of $690 \mathrm{~V}$, stator current of $1300 \mathrm{~A}$, stator voltage frequency of $50 \mathrm{~Hz}$, rotor speed of $1800 \mathrm{rpm}$ and efficiency of $96.5 \%$. According to Section III, the MSB detector, as a type of higher-order spectral analysis method, is effective only if the current fluctuations are small. Even though the torque and speed of the wind turbine usually change with wind conditions, the generator speed will stay constant at $1080 \mathrm{rpm}$ in the low-power level $(50 \mathrm{~kW})$, which provides the opportunity for applying the MSB method in the current signal analysis.

The diagram of the DFIG based electrical drive train is shown in Fig. 4. Current signals in the DFIG stator winding are monitored by the connected converter to control the generator power. In the tested wind turbine, the generator is installed in the nacelle, and the converter is situated at the bottom of the tower (Fig. 5). Since the measurement of the stator current uses the sensor located at the busbar of the converter, the current-based bearing fault detection does not require additional hardware.

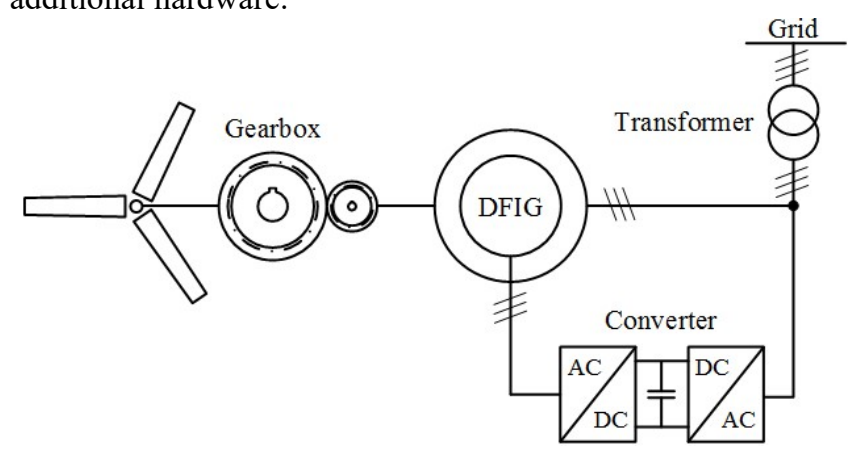

Fig. 4. Block diagram of the DFIG based wind power generation system.

Current waveforms within a period of time are recorded by power converters when a certain trigger condition is met. Since the data acquisition process uses the existing high-speed sampling module on the power converters, the sampling frequency and sampling time of $\mathrm{A} / \mathrm{D}$ conversion will remain invariant at $1 \mathrm{kHz}$ and $5.5 \mathrm{~s}$, respectively. Then, the stored data in the converter are uploaded to the host computer by series communication for further calculations. To determine the fault frequency of bearings, the generator speed will also be recorded by an encoder with the same sampling frequency and duration. However, the bispectral method cannot directly analyse non-stationary current signals because of its amplitude fluctuation and variation of characteristic frequency. According 
to the existing sampling frequency and time, the number of sampling points per segment for the DFT is $M=2^{12}=4096$, therefore, the minimum frequency resolution will be $\Delta f=$ $1 / 4.096=0.244 \mathrm{~Hz}$. On account of this frequency resolution and the outer raceway characteristic frequency in (4), the limitation for speed variation should be $4 \mathrm{rpm}$. Since the output power varies with wind speed according to the power curve of the wind turbine [43], the amplitude of the stator current will be relatively invariant at a constant speed. Then, the MSB analysis is applied to those data that meet the speed limitation to seek the modulation frequency. The data acquisition and processing stages are shown in Fig. 6.

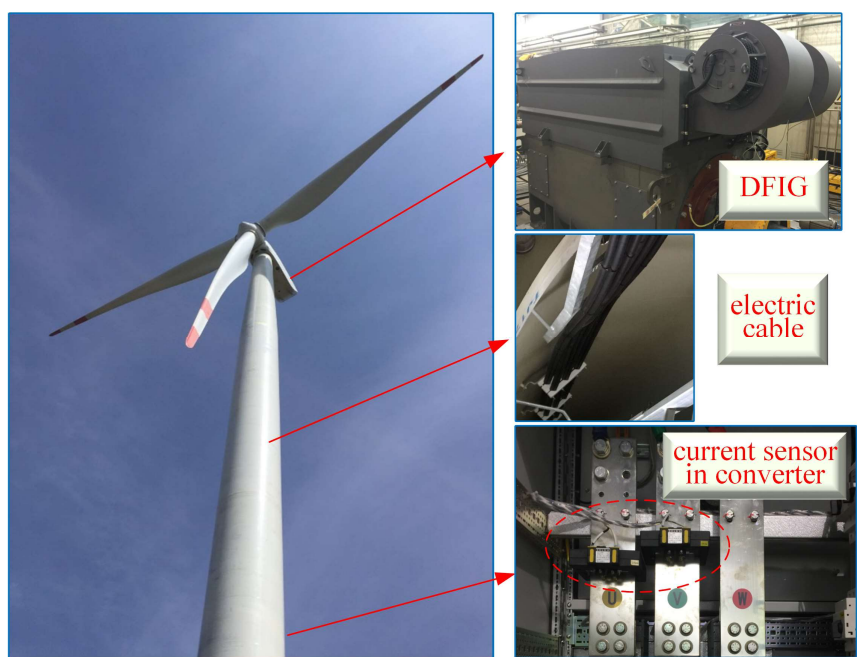

Fig. 5. Experimental set-up using an in situ 1.5 MW wind turbine.

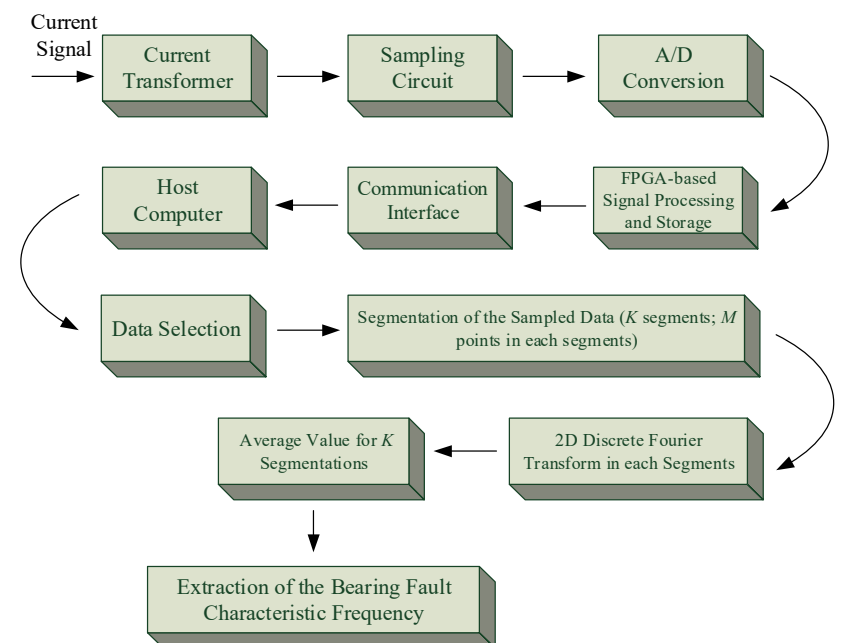

Fig. 6. Bearing fault diagnosis stages based on current signals.

\section{Validation of Field Results}

\section{A. Current Signal Analysis Based on the MSB Algorithm}

The proposed algorithm is tested on all generators in the chosen wind farm: because the data are collected in similar wind conditions, MSB results could be compared to evaluate the condition of the bearings. For the ball bearing shown in Fig. 3 , outer raceway damage is more likely to happen because of the centripetal force exerted by the roller balls. In the $1.5 \mathrm{MW}$
DFIG, the type of bearing in both driven and non-driven ends is an SKF 6330 C3. During site inspection of a regular maintenance, a bearing is judged to be faulty by monitoring abnormal noise and vibration. To validate the proposed algorithm, current signals are recorded before, and after, replacement of the faulty bearing. Meanwhile, other components in the wind turbine remain unchanged. Figs 7 and 8 show the comparison of two segments of acquired data consisting of stator current and rotor speed; because the average values of rotor speed in the two conditions are the same at $1085.5 \mathrm{rpm}$ and the fluctuation of the smoothed speed is within $4 \mathrm{rpm}$, the two segments of data are valid and comparable.

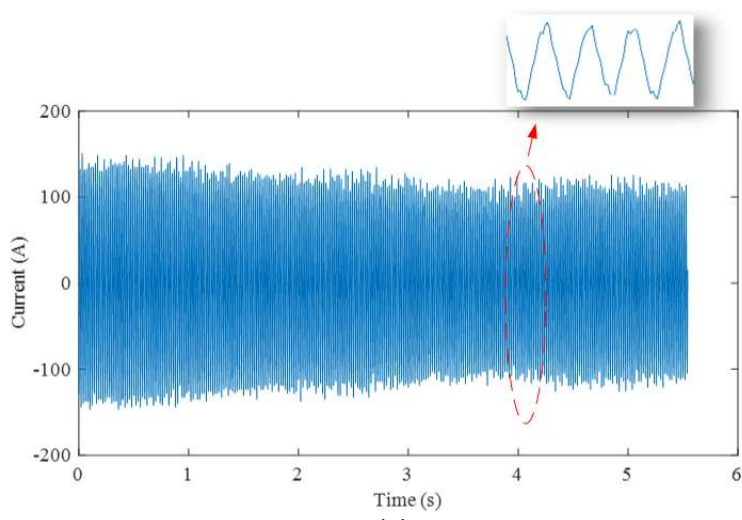

(a)

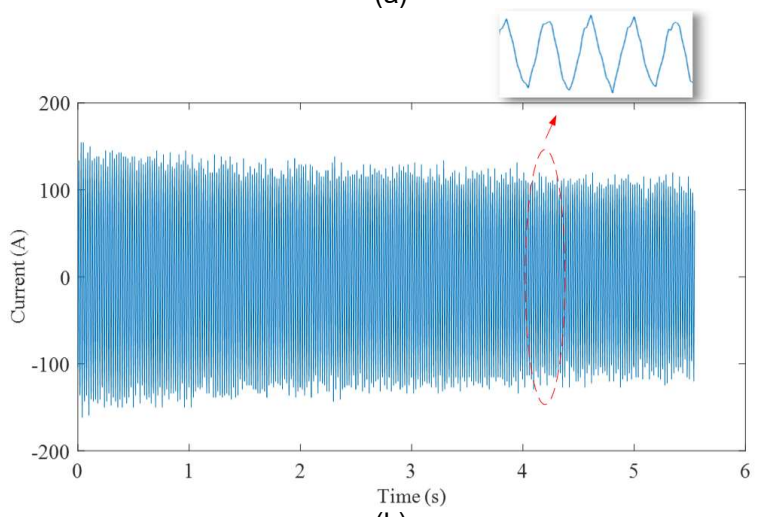

(b)

Fig. 7. Waveform of one-phase stator current in time domain: (a) faulty bearing and (b) healthy bearing.

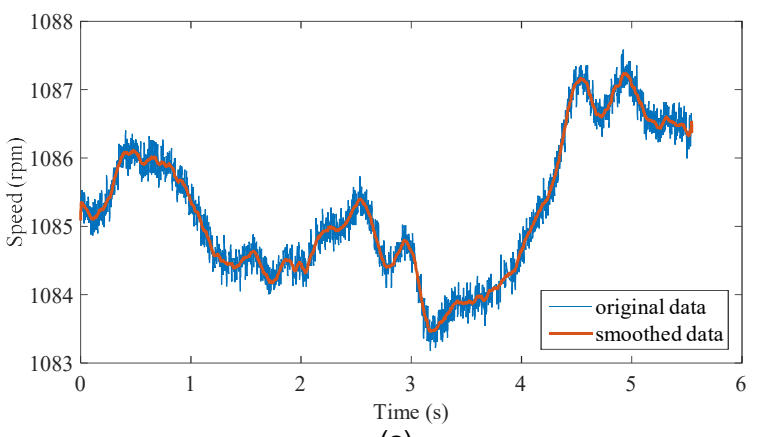

(a) 


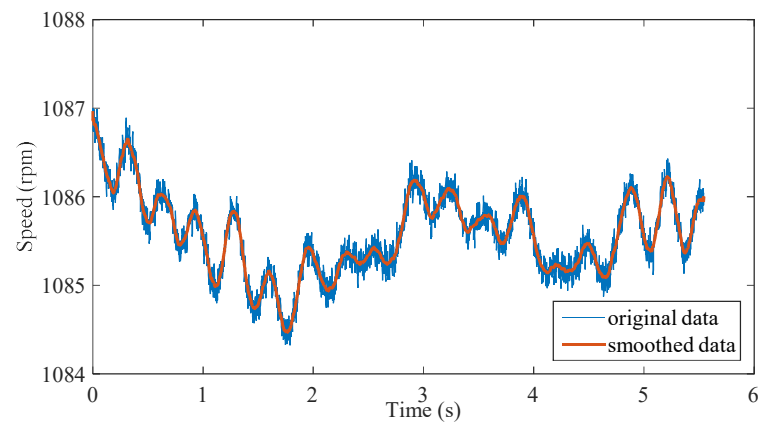

(b)

Fig. 8. Waveform of rotor speed in time domain: (a) faulty bearing and (b) healthy bearing.

From the comparison, it is difficult to ascertain the difference caused by bearing failure between two periods of the current signal in the time domain. After applying the Hanning window to the recorded current signal, the FFT results for the whole spectrum from 0 to $300 \mathrm{~Hz}$ are compared. Three visible differences in peaks of components for faulty and healthy bearing are marked in Fig. 9. Since the amplitudes of the faulty bearing are greater than that of the healthy bearing at $|50 \pm 64.9|$ $\mathrm{Hz}, 64.9 \mathrm{~Hz}$ might be a characteristic frequency caused by mechanical modulation due to (9) at a certain speed. Hence, another significant difference that only appears at $(50+35.9)$ $\mathrm{Hz}$ cannot correspond with the mechanical modulated fault, which has little impact on the bearing. Although the current spectrum reflects some differences before, and after, replacement of the bearing, the fault still cannot be confirmed because the phase relationship in (10) is not revealed. To address this issue, the proposed method on the basis of the MSB detector is applied. According to amplitude differences in the frequency domain, the range of modulation frequencies for the MSB detector is set as 30 to $80 \mathrm{~Hz}$. From (11), the magnitude of $B\left(f_{m}, f_{c}\right)$ is an indicator used to quantify the modulation effect of two components with different frequencies in one piece of data. Since the fundamental frequency of the stator current in the DFIG corresponds to the grid frequency, the carrier wave frequency $f_{c}$ will be $50 \mathrm{~Hz}$. From the analysis in Sections II and III, the modulation frequency $f_{m}$ caused by the outer raceway failure in the SKF $6330 \mathrm{C} 3$ bearing is $64.9 \mathrm{~Hz}$ at a rotor speed of $1085.5 \mathrm{rpm}$. Hence, MSB results around $f_{m}=64.9 \mathrm{~Hz}$ and $f_{c}=$ $50 \mathrm{~Hz}$ should be focused on to identify bearing faults from these recorded data. As shown in Fig. 10, the amplitude for the faulty bearing is distinguished from that for the healthy bearing only at $f_{m}=64.9 \mathrm{~Hz}$ and $f_{c}=50 \mathrm{~Hz}$, which represents the different modulation effect between the ball pass frequency of the outer-race and the fundamental frequency of the stator current. Meanwhile, MSB results also show that the peak does not appear at $f_{m}=35.9 \mathrm{~Hz}$ for the generator with a faulty bearing. Another bispectrum peak occurring at $f_{m}=42.6 \mathrm{~Hz}$ have similar values for both faulty and healthy bearings, which might be caused by other components in the mechanical drive chain of the wind turbine.

To locate the faulty area of the bearing, the characteristic frequencies for the inner raceway, the outer raceway, the ball, and the cage are compared before, and after, replacement of the faulty bearing. As shown in Fig. 11, the amplitude of the ball pass frequency of the outer-race (BPFO) can be significantly reduced while the other amplitudes at the ball pass frequency of the inner-race (BPFI), the fundamental train frequency (FTF), and the ball spin frequency (BSF) are quasi-invariant. Based on the comparison of MSB results, the failure location of this bearing is determined as the outer raceway.

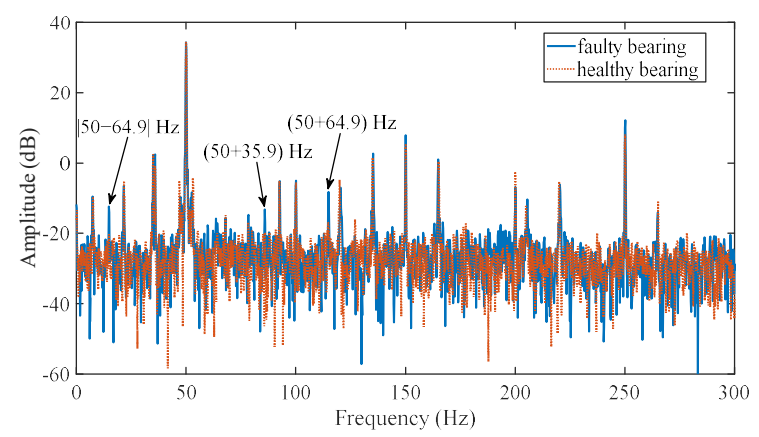

Fig. 9. Comparison of current spectra for a faulty and a healthy bearing.

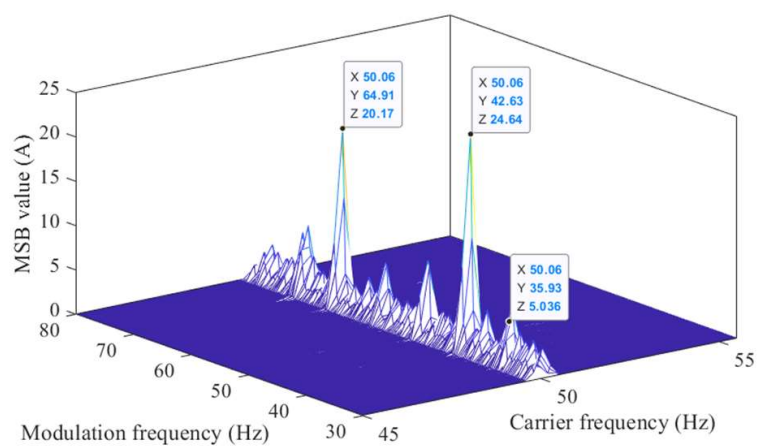

(a)

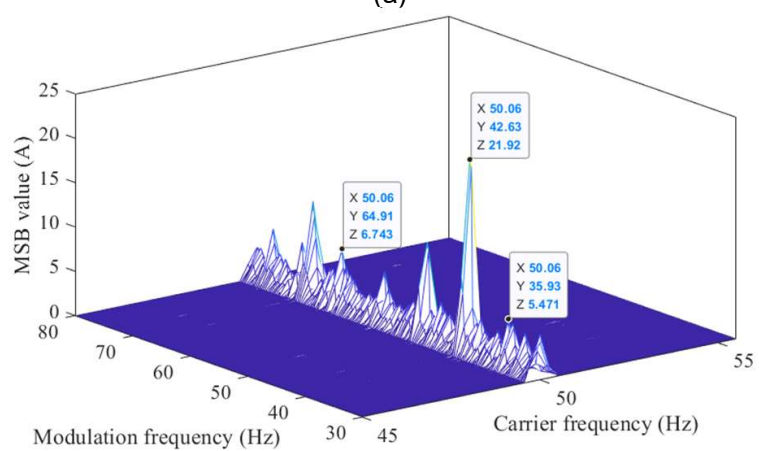

(b)

Fig. 10. MSB results of the current signal: (a) faulty bearing and (b) healthy bearing.

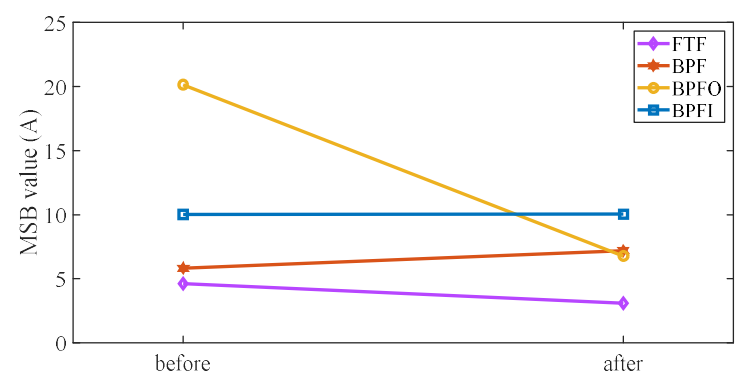

Fig. 11. Comparison of the characteristic frequency before, and after, replacement of the faulty bearing. 


\section{B. Validation of Bearing Condition}

The substituted bearing is disassembled to check the failure location and severity. As shown in Fig. 12, the ball bearing of a 1.5 MW generator is cut open to inspect the raceway of the bearing. The colour of the grease in this bearing has turned to black due to overheating. After cleaning the lubricant grease, the corrugated groove caused by electrical corrosion is clearly visible at the outer raceway of the bearing. These regular grooves cause the characteristic frequency of vibration and modulate the electromagnetic torque of the generators, therefore, the bearing defect caused by electrical corrosion can be identified by the distinction between MSB results from Figs 10 and 11.

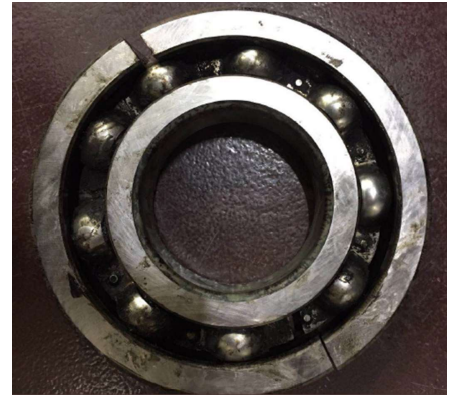

(a)

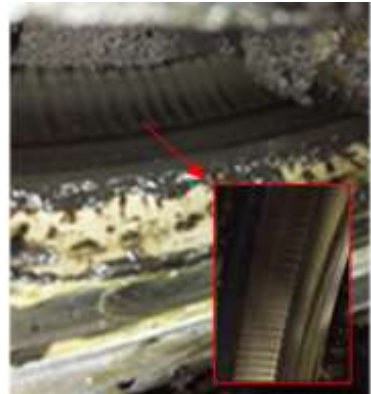

(b)
Fig. 12. The replaced faulty bearing caused by current corrosion: (a) outline of the replaced bearing and (b) corrugated grooves in the outer raceway.

\section{ANALYSIS Of DIAGNOSIS RESULTS}

\section{A. Comparison of Different Data Processing Methods}

To confirm the advantage of the proposed current-based diagnosis method, a contrastive study should be undertaken with other common data processing methods. For bearing fault detection, power spectral estimation, EPVA, and Hilbert transform-based envelope analysis have been proven to be effective for stationary signals [12], [15], [16]. Thus, the performance of the proposed method based on an MSB detector should be compared with the performance of these three conventional methods. Some restrictions in the comparison are as follows: 1) different algorithms are applied to the same data, 2) the current data should be converted to per unit values, 3) calculation results are expressed in decibels $(\mathrm{dB})$, and 4) the Hanning window is applied to all records.

To highlight the difference between faulty and healthy bearings, the MSB results should be plotted on the same graph. Thus, the 3-d results in Fig. 10 are converted to 2-d format by only retaining $f_{m}$ when $f_{c}$ is around $50 \mathrm{~Hz}$. As can be seen from the comparison of MSB results shown in Fig. 13, the magnitude of the outer-race characteristic frequency for the faulty bearing is much larger than that of the healthy bearing, meanwhile the variation of other harmonic components is small. The diagnosis of a bearing fault can rely on this contrast at a certain frequency based on MSB analysis.

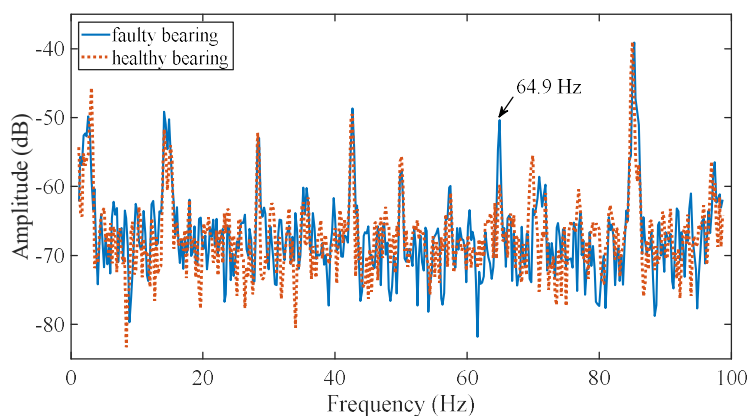

Fig. 13. Comparison of current spectra by the MSB method.

The estimation of the power spectral density has been a useful tool in digital signal processing for more than fifty years, and has been applied in bearing fault diagnosis [29]. The amplitude comparison of the power spectra for the two segments of current data is presented in Fig. 14. Since harmonic frequencies of the stator current caused by bearing corrosion are $114.9 \mathrm{~Hz}$ and $14.9 \mathrm{~Hz}$ according to (9), consideration should be given to both frequencies. In addition, the visible difference persists at the single side band of $85.9 \mathrm{~Hz}$ in the power spectrum, which is not caused by the mechanical modulated fault.

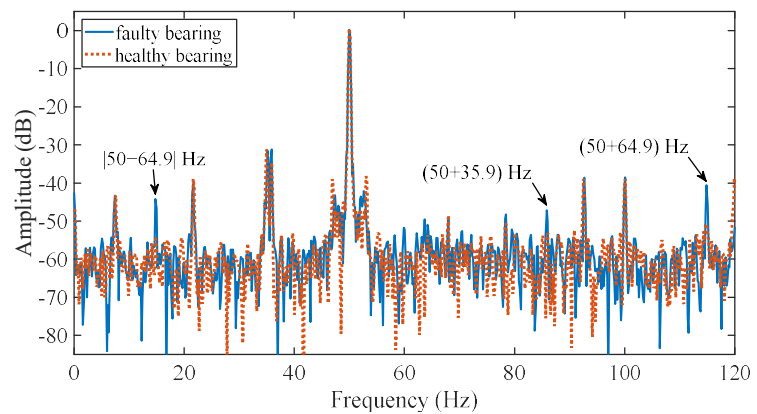

Fig. 14. Comparison of power spectra for current signals.

The Park's vector can convert balanced frequency components in three phases to a dc signal, which improves the signal to noise ratio and merges two harmonic components [44]. The d-q components of Park's vector can be obtained from three phase current data as follows [45]:

$$
\begin{gathered}
i_{d}=\frac{\sqrt{2}}{\sqrt{3}} i_{a}-\frac{1}{\sqrt{6}} i_{b}-\frac{1}{\sqrt{6}} i_{c} \\
i_{q}=\frac{1}{\sqrt{2}} i_{b}-\frac{1}{\sqrt{2}} i_{c}
\end{gathered}
$$

where $i_{a}, i_{b}$, and $i_{c}$ are three phase currents in the stator windings. The value of $i_{c}$ can be calculated, from the other two phase current data, as

$$
i_{c}=-\left(i_{a}+i_{b}\right) .
$$

Then, the square of Park's vector in (25), which is to be analysed in the frequency domain, will only contain unbalanced harmonic components. This method is called the EPVA.

$$
I_{s}=\left|i_{d}+j i_{q}\right|^{2}
$$

Moreover, the EPVA also transforms the harmonic frequency of $f_{s} \pm i f_{\text {fault }}$ in the current signal to $i f_{\text {fault }}$. Therefore, 
the characteristic frequency of the Park's vector can be extracted using spectral analysis, which has successfully diagnosed the bearing fault by way of an analysis of the current signals; however, one more phase of current date should be monitored to calculate the Park's vector in contrast with the MSB method, which needs more data storage space. The spectral comparison of the faulty and the healthy bearings using EPVA is shown in Fig. 15. Even though the difference of BPFO at $64.9 \mathrm{~Hz}$ is obvious, visible differences still remain at other frequencies such as $20.4 \mathrm{~Hz}, 35.9 \mathrm{~Hz}$, and $77 \mathrm{~Hz}$. These three frequencies are not characteristic frequencies of the bearing according to (3)-(6). For the reason that two records are acquired before, and after, replacement of one bearing in the DFIG in the same condition, the differences can only be caused by the bearing. Therefore, additional peaks in the spectrum may impede fault diagnosis.

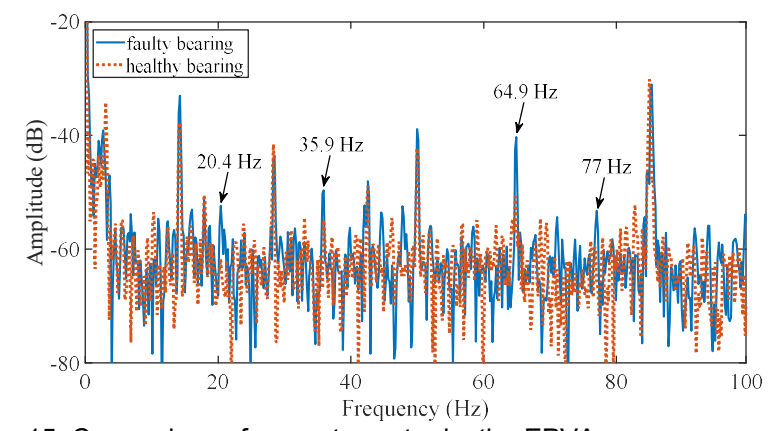

Fig. 15. Comparison of current spectra by the EPVA.

The Hilbert demodulation-based envelope analysis is another regular data processing method used in bearing fault diagnosis. The procedure used in this method is usually described by the following four steps [12]: Step-1, computation of the Hilbert transform of the sampled data; Step-2, computation of the upper envelope of the signal; Step-3, filtering of the dc component of the envelope signal; and Step-4, computation of the Fourier transform of the filtered envelope signal. Hence, it is possible to retrieve the component at the characteristic frequency of the bearing. The variations in envelope spectrum amplitudes for healthy, and faulty, cases are compared in Fig. 16. Similar to the result arising from use of EPVA, more visible differences occur at $35.9 \mathrm{~Hz}, 50 \mathrm{~Hz}$ and 87 $\mathrm{Hz}$.

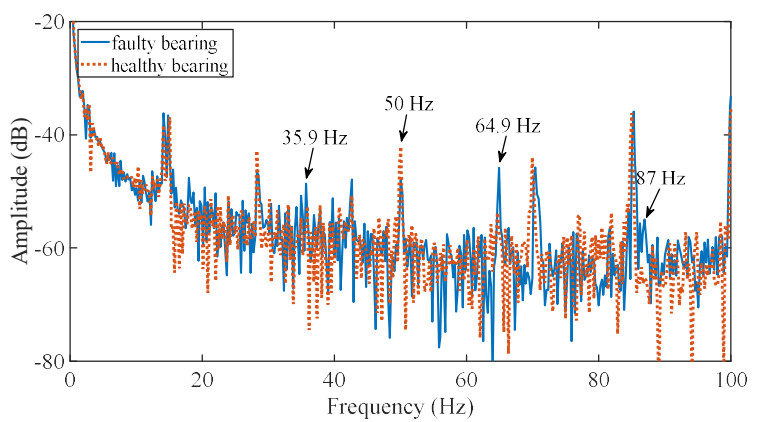

Fig. 16. Comparison of current spectra by Hilbert transform-based envelope analysis.

From Figs 13 to 16, the amplitude for BPFO of the faulty bearing is greater than that of a healthy bearing; however, additional visible differences in the power spectrum, the EPVA spectrum, and the envelope spectrum may lead to misdiagnosis of the bearing fault. For example, the amplitude peaks at 35.9 $\mathrm{Hz}$ appearing in both the EPVA spectrum and the envelope spectrum are caused by the harmonic component of $50+35.9=$ $85.9 \mathrm{~Hz}$ in the power spectrum (this peak disappears in the MSB result). The reason is that the MSB detector not only analyses the amplitude of the harmonic components but also takes the phase information into account. Since the QPC in the AM cannot be identified by algorithms based on single spectrum (the second order spectrum), the algorithm, when applied to the bispectrum, will be effective, accurate, and incurs low computational cost.

Based on this analysis, the results among the four data processing methods in the specific case of bearing fault diagnosis using the approximately stationary current data are compared, as shown in Table I. Due to its relatively high accuracy and low data storage requirement, the MSB algorithm may be an appropriate method of current-based bearing fault diagnosis.

TABLE I

Comparison of DAta PRocessing Methods Using CuRRENT Data

\begin{tabular}{|c|c|c|c|c|}
\hline Property & $\begin{array}{c}\text { MSB } \\
\text { method }\end{array}$ & $\begin{array}{l}\text { Power } \\
\text { spectral }\end{array}$ & EPVA & $\begin{array}{c}\text { Envelope } \\
\text { analysis }\end{array}$ \\
\hline Domain & Frequency & Frequency & Frequency & Time \\
\hline $\begin{array}{l}\text { Frequency } \\
\text { extraction }\end{array}$ & Yes & Yes & Yes & Yes \\
\hline $\begin{array}{l}\text { Detecting } \\
\text { the QPC }\end{array}$ & Yes & No & No & No \\
\hline Complexity & High & Low & Medium & Medium \\
\hline $\begin{array}{l}\text { Data storage } \\
\text { space }\end{array}$ & Low & Low & High & Low \\
\hline
\end{tabular}

\section{B. Condition Monitoring based on Current Signals}

Since the vibration condition monitoring system (VCMS) is a fully validated technology used for fault diagnosis in bearings, results from the MSB method can be compared with the amplitude of the acceleration envelope to confirm the bearing condition. Ten wind turbines were monitored with both vibration signals and electrical signals. The comparison between the current and vibration-based diagnoses is summarised in Table II. Since the trend in the variation of the MSB magnitude at the BPFO is the same as that of the VCMS results, the current-based index can reflect the vibration amplitude of the bearing. According to VCMS results and physical inspection reports, the bearing has a high risk of outer race failure if the MSB amplitude is greater than $-53 \mathrm{~dB}$. Therefore, the proposed technique is validated on multiple wind turbines with the presence of defects of different severities.

From above analysis and validation, vibration information hidden in current signals of the electric machine can be extracted by the MSB method. To prevent the occurrence of faults, the MSB value of the current signal requires long-term monitoring. Among several components in the ball bearing, the outer raceway is more apt to be impacted by roller balls. Thus, 
the magnitude of $B\left(f_{o}, f_{s}\right)$ will be an essential criterion in bearing fault diagnosis. Having recorded current data for one month, the variation of the outer raceway MSB value from two monitored wind turbines is plotted in Fig. 17. By curve fitting with an exponential function, the rising trend in Fig. 17(a) can be seen to represent the development of bearing abrasion caused by electrical corrosion or some other reasons. Meanwhile, the bearing shown in Fig. 17(b) operates in a relatively stable state.

TABLE II

COMPARISON OF DIAGNOSES: CURRENT AND VIBRATION SIGNALS

\begin{tabular}{cccc}
\hline \hline $\begin{array}{c}\text { Bearing } \\
\text { number }\end{array}$ & $\begin{array}{c}\text { MSB amplitude of } \\
\text { the BPFO }(\mathrm{dB})\end{array}$ & $\begin{array}{c}\text { Envelope amplitude of } \\
\text { the VCMS }\left(\mathrm{m} / \mathrm{s}^{2}\right)\end{array}$ & $\begin{array}{c}\text { Severity of } \\
\text { failure }\end{array}$ \\
\hline 1 & -60.18 & 3.71 & Healthy \\
2 & -51.8 & 46.32 & Incipient fault \\
3 & -52.22 & 34.11 & Incipient fault \\
4 & -49.62 & 69.49 & Incipient fault \\
5 & -59.16 & 3.87 & Healthy \\
6 & -51.39 & 41.93 & Incipient fault \\
7 & -48.42 & 97.24 & Serious fault \\
8 & -57.41 & 17.37 & Healthy \\
9 & -48.7 & 71.21 & Serious fault \\
10 & -59.16 & 6.11 & Healthy \\
\hline \hline
\end{tabular}

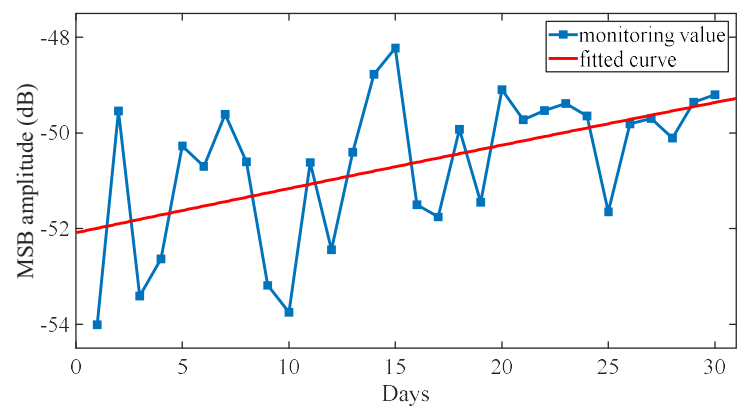

(a)

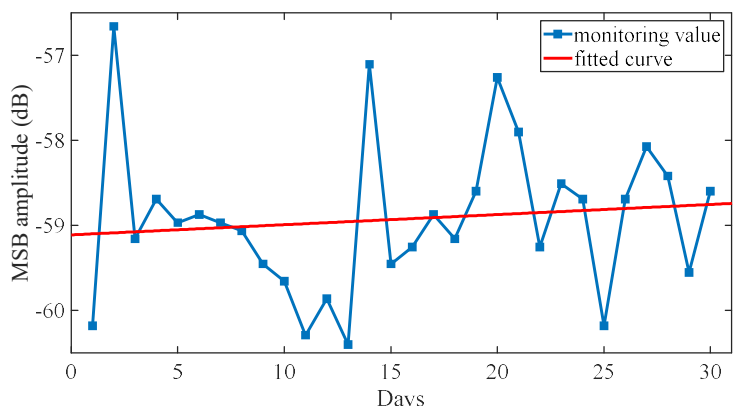

(b)

Fig. 17. Condition monitoring based on current signals: (a) incipient faulty bearing and $(b)$ healthy bearing.

\section{CONCLUSION}

A bearing fault detection method based on the analysis of current signals is proposed. An MSB detector has been applied to the analysis of the amplitude and phase of harmonic components in the stator current of the DFIG. Since vibration caused by bearing faults leads to the QPC and the AM in current signals, the MSB algorithm is found to be an effective, space-saving method with which to retrieve modulation information from data, while traditional methods based on a single spectrum are only concerned with the amplitude.

By using overlapped segmentation on the current data obtained from converters under certain conditions, the accuracy of the proposed method can be increased by averaging MSB detection results for each record. Therefore, the successful diagnosis of bearing failure caused by electrical corrosion in a 1.5 MW DFIG was realised. Moreover, fault location and assessment of fault severity can also be distinguished by the frequency and amplitude of the modulated signal. After field verification by vibration VCMS and bearing disassembly and inspection, the current-based bearing fault diagnosis using the MSB algorithm shows great benefits in industrial applications owing to its being non-invasive and low-cost.

\section{REFERENCES}

[1] M. Nick, G. Riahy, S. Hosseinian, and F. Fallahi, "Wind power optimal capacity allocation to remote areas taking into account transmission connection requirements," IET Renewable Power Gener., vol. 5, no. 5, pp. 347-355, Sep. 2011.

[2] W. Qiao and D. Lu, "A survey on wind turbine condition monitoring and fault diagnosis - part I: components and subsystems," IEEE Trans. Ind. Electron., vol. 62, no. 10, pp. 6536-6545, Oct. 2015.

[3] Y. Amirat, M. E. H. Benbouzid, B. Bensaker, and R. Wamkeue, "Condition monitoring and fault diagnosis in wind energy conversion systems: a review," in Proc. IEEE Int. Conf. Elec. Mach. Driv. pp. 1434-1439, Antalya, Turkey, 3-5 May. 2007.

[4] A. Bellini, F. Filippetti, C. Tassoni, and G. A. Capolino, "Advances in diagnostic techniques for induction machines," IEEE Trans. Ind. Electron., vol. 55, no. 12, pp. 4109-4126, Dec. 2008.

[5] T. Plazenet, T. Boileau, C. Caironi and B. Nahid-Mobarakeh, "A comprehensive study on shaft voltages and bearing currents in rotating machines," IEEE Trans. Ind. Appl., vol. 54, no.4, pp. 3749-3759, July./Aug. 2018

[6] W. Qiao and D. Lu, "A survey on wind turbine condition monitoring and fault diagnosis - part II: signals and signal processing methods," IEEE Trans. Ind. Electron., vol. 62, no.10, pp. 6546-6557, Oct. 2015.

[7] P. Zhang and P. Neti, "Detection of gearbox bearing defects using electrical signature analysis for doubly fed wind generators," IEEE Trans. Ind. Appl., vol. 51, no.3, pp. 2195-2200, May./Jun. 2015

[8] M. Blodt, P. Granjon, B. Raison, and G. Rostaing, "Models for bearing damage detection in induction motors using stator current monitoring," IEEE Trans. Ind. Electron., vol. 55, no. 4, pp. 1813-1822, Apr. 2008.

[9] C. M. Riley, B. K. Lin, T. G. Habetler and R. R. Schoen, "A method for sensorless on-line vibration monitoring of induction machines," IEEE Trans. Ind. Appl., vol. 34, no.6, pp. 1240-1245, Nov./Dec. 1998.

[10] V. C. M. N. Leite, D. S. J. G. Borges, G. F. Cintra Veloso, and D. S. L. E. Borges, "Detection of localized bearing faults in induction machines by spectral kurtosis and envelope analysis of stator current," IEEE Trans. Ind. Electron., vol. 62, no. 3, pp. 1855-1865, Mar. 2015.

[11] X. An, D. Jiang, S. Li, and M. Zhao, "Application of the ensemble empirical mode decomposition and Hilbert transform to pedestal looseness study of direct-drive wind turbine, " Energy, vol. 36, no. 9, pp. 5508-5520, Sep. 2011

[12] F. Immovilli, A. Bellini, R. Rubini, and C. Tassoni, "Diagnosis of bearing faults in induction machines by vibration or current signals: a critical comparison," IEEE Trans. Ind. Appl., vol. 46, no. 4, pp. 1350-1359, July./Aug. 2010.

[13] E. Elbouchikhi, V. Choqueuse, Y. Amirat, M. E. H. Benbouzid, and S. Turri, "An efficient Hilbert-Huang Transform-based bearing faults detection in induction machines," IEEE Trans. Energy Convers., vol. 32, no. 2, pp. 401-413, Jun. 2017.

[14] S. E. Pandarakone, Y. Mizuno and H. Nakamura, "Distinct fault analysis of induction motor bearing using frequency spectrum determination and support vector machine," IEEE Trans. Ind. Appl., vol. 53, no.3, pp. 3049-3056, May./Jun. 2017.

[15] J. L. H. Silva and A. J. M. Cardoso, "Bearing failures diagnosis in three-phase induction motors by extended Park's vector approach," in Proc. the 31st Annual Conf. of IEEE Ind. Electron. Society, pp. 6, 
Raleigh, NC, 6-10 Nov. 2005.

[16] H. Ahmadi and A. Moosavian, "Fault diagnosis of journal-bearing of generator using power spectral density and fault probability distribution function," in Proc. the 1st Int. Conf. Inno. Comp. Tech., pp. 30-36, Amsterdam, 2011.

[17] C. P. Mbo'O and K. Hameyer, "Fault diagnosis of bearing damage by means of the linear discriminant analysis of stator current features from the frequency selection," IEEE Trans. Ind. Appl., vol. 52, no. 5, pp. 3861-3868, Sept./Oct. 2016

[18] A. H. Boudinar, N. Benouzza, A. Bendiabdellah, and M. E. A. Khodja, "Induction motor bearing fault analysis using a root-MUSIC method," IEEE Trans. Ind. Appl., vol. 52, no. 5, pp. 3851-3860, Sept./Oct. 2016.

[19] F. Dalvand, M. Kang, S. Dalvand, and M. Pecht, "Detection of generalized-roughness and single-point bearing faults using linear prediction-based current noise cancellation," IEEE Trans. Ind. Electron., vol. 65 , no. 12, pp. 9728-9738, Dec. 2018.

[20] X. Gong and W. Qiao, "Bearing fault diagnosis for direct-drive wind turbines via current-demodulated signals," IEEE Trans. Ind. Electron., vol. 60 , no. 8, pp. 3419-3428, Aug. 2013.

[21] R. Tao, Y. L. Li, and Y. Wang, "Short-time fractional Fourier transform and its applications," IEEE Trans. Signal Process., vol. 58, no. 5, pp. 2568-2580, May. 2010.

[22] S. Singh and N. Kumar, "Detection of bearing faults in mechanical systems using stator current monitoring," IEEE Trans. Ind. Inform., vol. 13, no. 3, pp. 1341-1349, Jun. 2017.

[23] F. B. Abid, S. Zgarni and A. Braham, "Distinct bearing faults detection in induction motor by a hybrid optimized SWPT and aiNet-DAG SVM,' IEEE Trans. Energy Convers., vol. 33, no. 4, pp. 1692-1699, Dec. 2018.

[24] M. Schlechtingen, I. F. Santos, and S. Achiche, "Wind turbine condition monitoring based on SCADA data using normal behavior models. Part 1: System description," J. Appl. Soft Comput., vol. 13, pp. 259-270, 2013.

[25] G. Li and J. Shi, "Applications of Bayesian methods in wind energy conversion systems," Renewable Energy, vol. 43, pp. 1-8, Jul. 2012

[26] S. S. Refaat, H. Abu-Rub, M. S. Saad, E. M. Aboul-Zahab, and A. Iqbal, "ANN-based for detection, diagnosis the bearing fault for three phase induction motors using current signal," in Proc. IEEE Int. Conf. Ind. Technol. (ICIT), pp. 253-258, Cape Town, South Africa, 2013.

[27] T. I. Liu and J. H. Singonhalli, "Detection of roller bearing defects using expert system and fuzzy logic,” Mech. Syst. Signal Process., vol. 10, no. 5, pp. 595-614, 1996.

[28] J. R. Stack, T. G. Habetler and R. G. Harley, "Fault classification and fault signature production for rolling element bearings in electric machines," IEEE Trans. Ind. Appl., vol. 40, no. 3, pp. 735-739, May./Jun. 2004.

[29] C. L. Nykias and J. M. Mendel, "Signal processing with higher-order spectra," IEEE Signal Process. Mag., vol. 10, no. 3, pp. 10-37, Jul. 1993.

[30] J. R. Stack, R. G. Harley and T. G. Habetler, "An amplitude modulation detector for fault diagnosis in rolling element bearings," IEEE Trans. Ind. Electron., vol. 51, no.5, pp. 1097-1102, Oct. 2004.

[31] O. Hamomd, S. Alabied, Y. Xu, A. Daraz, F. Gu, and A. Ball, "Vibration based centrifugal pump fault diagnosis based on modulation signal bispectrum analysis," in Int. Conf. on Auto. \& Comp., pp. 1-5, Huddersfield, UK, 7-8 Sept. 2017

[32] A. Alwodai, X. Yuan, Y. Shao, F. Gu, and A. D. Ball, "Modulation signal bispectrum analysis of motor current signals for stator fault diagnosis," in Int. Conf. on Auto. \& Comp., pp. 1-6, Loughborough, UK, 7-8 Sept. 2012.

[33] F. Immovilli, C. Bianchini, M. Cocconcelli, A. Bellini and R. Rubini, "Bearing fault model for induction motor with externally induced vibration," IEEE Trans. Ind. Electron., vol. 60, no. 8, pp. 3408-3418, Aug. 2013.

[34] M. Ojaghi, M. Sabouri and J. Faiz, "Analytic model for induction motors under localized bearing faults," IEEE Trans. Energy Convers., vol. 33 , no. 2, pp. 617-626, Jun. 2018.

[35] T. Zika, I. C. Gebeshuber, F. Buschbeck, G. Preisinger and M. Gröschl, "Surface analysis on rolling bearings after exposure to defined electric stress," Proc. IMechE Vol. 223 Part J: J. Engineering Tribology, vol. 223, no. Part J: J. Engineering Tribology, pp. 787-797, 2008.

[36] S. Chen, T. A. Lipo and D. Fitzgerald, "Modeling of motor bearing currents in PWM inverter drives," IEEE Trans. Ind. Appl., vol. 32, no. 6, pp. 1365-1370, Nov./Dec. 1996.

[37] J. Kalaiselvi and S. Srinivas, "Bearing currents and shaft voltage reduction in dual-inverter-fed open-end winding induction motor with reduced CMV PWM methods," IEEE Trans. Ind. Electron., vol. 62, no. 1 , pp. 144-152, Jan. 2015

[38] J. Zitzelsberger, W. Hofmann, A. Wiese and P. Stupin, "Bearing currents in doubly-fed induction generators," in Proc. European Conference on Power Electronics and Applications, pp. 9, Dresden, 2005

[39] A. Muetze and A. Binder, "Practical rules for assessment of inverter-induced bearing currents in inverter-fed AC motors up to 500 kW," IEEE Trans. Ind. Electron., vol. 54, no. 3, pp. 1614-1622, June 2007.

[40] G. W. Buckley, R. J. Corkins and R. N. Stephens, "The importance of grounding brushes to the safe operation of large turbine generators," IEEE Trans. Energy Convers., vol. 3, no. 3, pp. 607-612, Sept. 1988.

[41] B. Li, M. -. Chow, Y. Tipsuwan and J. C. Hung, "Neural-network-based motor rolling bearing fault diagnosis," IEEE Trans. Ind. Electron., vol. 47, no. 5, pp. 1060-1069, Oct. 2000.

[42] M. Blodt, J. Regnier and J. Faucher, "Distinguishing load torque oscillations and eccentricity faults in induction motors using stator current Wigner distributions," IEEE Trans. Ind. Appl., vol. 45, no. 6, pp. 1991-2000, Nov./Dec. 2009.

[43] S. Gill, B. Stephen, and S. Galloway, "Wind turbine condition assessment through power curve copula modeling," IEEE Trans. Sustain. Energy, vol. 3, no. 1, pp. 94-101, Jan. 2012.

[44] A. J. Marques Cardoso, S. M. A. Cruz and D. S. B. Fonseca, "Inter-turn stator winding fault diagnosis in three-phase induction motors, by Park's vector approach," IEEE Trans. Energy Convers., vol. 14, no. 3, pp. 595-598, Sept. 1999.

[45] S. M. A. Cruz and A. J. M. Cardoso, "Stator winding fault diagnosis in three-phase synchronous and asynchronous motors, by the extended Park's vector approach," IEEE Trans. Ind. Appl., vol. 37, no. 5, pp. 1227-1233, Sept./Oct. 2001.

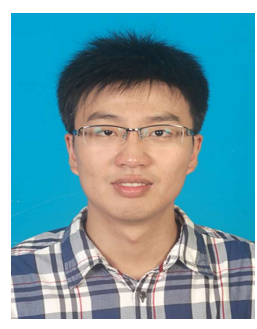

Xi Chen (S'15-M'18) received B.Eng. degree from Shenyang University of Technology, Shenyang, China, in 2012, and the Ph.D. degree from the Huazhong University of Science and Technology, Wuhan, China, in 2017, respectively, all in electrical engineering.

In 2012, he served as a teaching assistant at the School of Electrical and Electronic Engineering, Huazhong University of Science and Technology. Since 2019, He has been a Senior R\&D Engineer with the Envision Energy. His research interests include design and control of electrical machine systems, magnetic field modeling, harmonic analysis and renewable energy technologies.

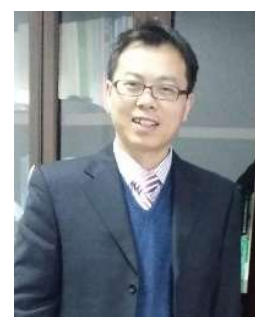

Wei Xu (M'09-SM'13) received the double B.E. and M.E. degrees from Tianjin University, Tianjin, China, in 2002 and 2005, and the Ph.D. from the Institute of Electrical Engineering, Chinese Academy of Sciences, in 2008, respectively, all in electrical engineering.

From 2008 to 2012, he held several academic positions in both Australian and Japanese universities and companies. Since 2013, he has been full professor with the State Key Laboratory of Advanced Electromagnetic Engineering and Technology, Huazhong University of Science and Technology, China. His research topics mainly cover design and control of linear/rotary machines.

$\mathrm{Dr}$. $\mathrm{Xu}$ is a Fellow of the Institute of Engineering and Technology (IET). He has served as Associate Editor for several Journals, such as IEEE Transactions on Industrial Electronics, IEEE Journal of Emerging and Selected Topics in Power Electronics, IEEE Transactions on Vehicular Technology, etc.

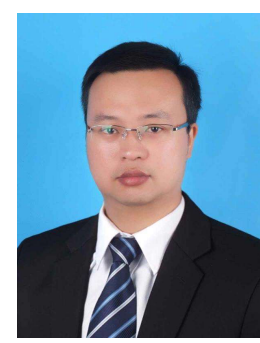

Yi Liu (M'14) received the B.E. and M.E. degrees in automation and control engineering from the Wuhan University of Science and Technology, Wuhan, China, in 2004 and 2007, respectively, and the Ph.D. degree in mechatronic engineering from the Huazhong University of Science and Technology, Wuhan, China, in 2016.

From 2007 to 2011, he was a Lecturer with the City College, Wuhan University of Science and Technology. From March 2016 to June 2016, he was a Senior R\&D Engineer with the Fourth Academy of China Aerospace Science and Industry Group, Wuhan. In July 2016, he became 
a Postdoctoral Research Fellow with the State Key Laboratory of Advanced Electromagnetic Engineering and Technology, School of Electrical and Electronic Engineering, Huazhong University of Science and Technology. His current research interests include ac electrical machine control and inverter systems.

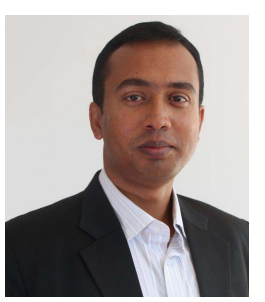

Md. Rabiul Islam (M'14-SM'16) received the B.Sc and M.Sc. degree from Rajshahi University of Engineering and Technology (RUET), Rajshahi, Bangladesh, in 2003 and 2009, respectively; and the

Ph.D. degree from University of Technology Sydney (UTS), Sydney, Australia, in 2014, all in electrical engineering.

He was appointed a lecturer at RUET in 2005 and promoted to full professor in 2017. In early 2018, he joined at the School of Electrical, Computer, and Telecommunications Engineering (SECTE), University of Wollongong (UOW), Wollongong, Australia. He is also a member of Australian Power Quality and Reliability Center of UOW. His research interests are in the fields of power electronic converters, renewable energy technologies, power quality, electrical machines, electric vehicles, and smart grid. He has served as a Guest Editor for IEEE Transactions on Energy Conversion and IEEE Transactions on Applied superconductivity. Currently he is editing a special issue for IET Electric Power Applications. 